\title{
CNS Glucagon-Like Peptide-1 Receptors Mediate Endocrine and Anxiety Responses to Interoceptive and Psychogenic Stressors
}

\author{
Kimberly P. Kinzig, ${ }^{1}$ David A. D’Alessio, ${ }^{3}$ James P. Herman, ${ }^{2}$ Randall R. Sakai, ${ }^{2}$ Torsten P. Vahl, ${ }^{3}$ Helmer F. Figueiredo, ${ }^{2}$ \\ Erin K. Murphy, ${ }^{2}$ and Randy J. Seeley ${ }^{2}$ \\ ${ }^{1}$ Department of Psychiatry and Behavioral Sciences, Johns Hopkins University School of Medicine, Baltimore, Maryland 21205, and Departments of \\ ${ }^{2}$ Psychiatry and ${ }^{3}$ Medicine, University of Cincinnati College of Medicine, Cincinnati, Ohio 45267-0559
}

\begin{abstract}
Responses to stressors serve to adjust physiology and behavior to increase short-term survival at the potential expense of increasing susceptibility to disease over the long term. We show that glucagon-like peptide-1 (7-36) amide (GLP-1) increases levels of the stressactivated hormones ACTH and corticosterone when administered directly into the rat brain and increases levels of anxiety as measured by the elevated plus maze. The endocrine response is preferentially activated by GLP-1 administration in the paraventricular nucleus of the hypothalamus, whereas the anxiety response is preferentially activated by administration in the central nucleus of the amygdala. Furthermore, GLP-1 antagonists block increases in stress hormones associated with the toxin LiCl and both the endocrine and anxiety responses to vertical heights. Although diverse neural circuits must necessarily process disparate stressors, the current data implicate a role for the GLP-1 system as a critical mediator of multiple stress responses.
\end{abstract}

Key words: GLP-1; interoceptive stress; psychogenic stress; glucocorticoids; central nucleus of the amygdala; paraventricular nucleus; anxiety

\section{Introduction}

When animals are subjected to stress, they generate a complex mix of physiological and behavioral responses. Although this stress response is critical for survival in the short term, when prolonged it contributes to deterioration of mental and physical health and has been associated with affective disorders such as depression and many systemic and neurodegenerative diseases (Kathol et al., 1989; Landfield and Eldridge, 1991; Charney et al., 1993; McEwen and Stellar, 1993; Grillon et al., 1996). Hence, the development and perpetuation of these disorders may result from prolonged exposure to a stress response that is initially beneficial to the animal's survival (Herman and Cullinan, 1997). The stress response is multifaceted and includes increased activity of the hypothalamic-pituitary-adrenal (HPA) axis and consequent elevated circulating glucocorticoids, as well as engagement in anxiety-related behaviors. Understanding the neural circuits that mediate these responses is a major goal for devising therapies aimed at reducing inappropriate stress responses.

Because stressors differ greatly in their forms, distinct neural pathways mediate their effects. For example, external threats such as the presence of predators or placement in a potentially dangerous location rely on forebrain pathways for recognizing the situation and generating a stress response. These psychogenic stres-

Received Dec. 17, 2002; revised May 1, 2003; accepted May 7, 2003.

This work was supported by National Institutes of Health Grant DK54890.

Correspondence should be addressed to Dr. Kimberly Kinzig, Johns Hopkins University, 720 Rutland Avenue, Ross 618, Baltimore, MD 21205. E-mail: kkinzig1@jhmi.edu.

Copyright $\odot 2003$ Society for Neuroscience $\quad$ 0270-6474/03/236163-08\$15.00/0 sors can be contrasted with physical injury and interoceptive stressors such as inflammation, hypoxia, and toxins, all of which generate a stress response with little, if any, cortical or cognitive input. In particular, interoceptive stressors rely on signals from brainstem pathways that integrate systemic information conveyed via the vagal and glossopharyngeal nerves, as well as signals transduced across the blood-brain barrier (Sawchenko et al., 2000). A number of CNS peptide signaling systems are implicated in stress responses, and corticotropin-releasing hormone (CRH) and related peptides in particular have been identified as key mediators of the stress response (Habib et al., 2001). However, pathways that stimulate the $\mathrm{CRH}$ system are diverse and not well understood. We report here that glucagon-like peptide-1 (7-36) amide (GLP-1) is a key neurotransmitter that mediates the response to disparate stressors.

CNS GLP-1 is a post-translational product of preproglucagon, produced in a discrete population of neurons in the nucleus of the solitary tract (NTS) (Han et al., 1986; Jin et al., 1988). GLP-1-producing neurons project to multiple brain areas, including many that are critical to stress responses. These include the central nucleus of the amygdala (CeA) and the paraventricular nucleus of the hypothalamus (PVN) (Goke et al., 1995), where high concentrations of GLP-1 receptors are found (Han et al., 1986; Merchenthaler et al., 1999). Considerable controversy has surrounded the function of GLP-1 in the CNS. The anatomy of this system, however, is ideally situated to provide interoceptive information from the caudal brainstem to the limbic structures implicated in mediating the responses to stress. It has been pre- 
viously demonstrated that GLP-1 neurons are activated in response to interoceptive stressors, such as the toxin $\mathrm{LiCl}$, and that central GLP-1 activates PVN CRH neurons (Larsen et al., 1997a; Rinaman, 1999a). We therefore hypothesized that central GLP-1 activates the HPA axis in response to interoceptive stressors. Additionally, because the anatomical location of GLP-1-producing neurons is limited to the brainstem, and data from others demonstrate the contribution of forebrain to PVN connections ( $\mathrm{Li}$ et al., 1996; Herman and Cullinan, 1997; Sawchenko et al., 2000) in mediating the response to psychogenic stressors (and relative lack of hindbrain to PVN contribution to PVN neuronal activation), we hypothesized that GLP-1 would not be involved in mediating the HPA response to psychogenic stressors.

\section{Materials and Methods}

\section{Experiment 1: GLP-1 and the HPA ais}

Ten male Long-Evans rats (275-350 gm) obtained from Charles River Laboratories (Wilmington, MA) were housed individually in plastic "tub" cages with a $12 \mathrm{hr}$ light/dark cycle. All rats were implanted with catheters in the inferior vena cava. Catheters were made of sterile SILASTIC tubing $(30 \mathrm{~cm}$ in length, 0.25 inch inner diameter, and 0.47 inch outer diameter; Fisher Scientific, Pittsburgh, PA), the distal end beveled, a small piece of sterile suture tied at $4 \mathrm{~cm}$ from the distal end, and filled with heparinized saline. The catheter was attached to a $1 \mathrm{ml}$ syringe filled with heparinized saline at the end that remained at the head. Under ketamine $(9 \mathrm{mg} / \mathrm{kg}$, i.p.) and xylazine $(1.5 \mathrm{mg} / \mathrm{kg}$, i.p.) anesthesia, the rat's abdomen and top of the head were shaved. A midline incision, $\sim 8$ $\mathrm{cm}$ in length, was made beginning at the sternum. An additional incision was made on the skull. The catheter was tunneled subcutaneously from the skull incision to the muscle wall lining the intraperitoneal cavity with a pair of straight hemostats. The muscle wall underlying the abdominal skin incision was opened. A small incision was made in the right muscle wall, through which the catheter was pulled into the intraperitoneal cavity. The inferior vena cava and surrounding area were cleared of fat by blunt dissection at the junction of the renal veins. Using blunt forceps, a tent was made of the inferior vena cava. The vein was then punctured with a 21 gauge needle, and the catheter was quickly inserted to the $4 \mathrm{~cm}$ mark. Heparinized saline $(0.5 \mathrm{ml})$ was slowly pushed through the inserted catheter. One suture was made in the dorsal muscle wall immediately to the right of the insertion site. An additional suture was made to tie the catheter to the muscle wall $3 \mathrm{~cm}$ to the right of the insertion site. A small amount of the catheter was then pulled into the abdominal cavity, and the muscle wall and skin were sutured. The rats were then given $3 \mathrm{ml}$ of warm saline subcutaneously. After the inferior vena cava catheterization, rats were stereotaxically implanted with third ventricular cannulas [ $-2.2 \mathrm{~mm}$ anteroposterior (AP) and $-7.5 \mathrm{~mm}$ dorsoventral (DV) with respect to bregma; Paxinos and Watson, 1997]. The catheter was cut at an appropriate length, attached to a blunted, bent 21 gauge needle (elbow), and fixed to the skull with anchor screws and dental acrylic, as was the cannula. The end of the catheter elbow was covered with a small piece of polyethylene tubing (PE 60) with the end sealed. Ten days after surgery, cannula placement was verified by administering angiotensin II (10 $\mathrm{nmol} / 1 \mu \mathrm{l}$ ) through the cannula [intracerebroventricular (i3vt)]. Rats that failed to drink at least $5 \mathrm{ml}$ of water in the $60 \mathrm{~min}$ after angiotensin II treatment were removed from the study. Catheter patency was also determined $10 \mathrm{~d}$ after surgery. A $1 \mathrm{ml}$ syringe was filled with saline and attached to $50 \mathrm{~cm}$ of PE 60 tubing. Saline was pushed through the tubing, and the tubing was attached to the catheter elbow on the skull. Saline $(0.2$ $\mathrm{ml}$ ) was pushed into the catheter, and blood was drawn to ensure patency. The blood was then pushed back into the catheter along with 0.6 $\mathrm{ml}$ of saline. Rats were handled daily for 1 week to acclimate them to the procedure (with the head cap and catheter). On test day 1 , a group of six rats received one of the following i3vt treatments: saline, $0.1 \mu \mathrm{g}$ of GLP-1, $1.0 \mu \mathrm{g}$ of GLP-1, or $10 \mu \mathrm{g}$ of GLP-1, all in a volume of $2 \mu \mathrm{l}$ (American Peptides, Sunnyvale, CA). Each rat was treated with each dose over a 3 week period, with no less than $5 \mathrm{~d}$ between each treatment. Testing began at $1 \mathrm{hr}$ past the onset of the light cycle. At this time, baseline blood was drawn into $\mathrm{K}^{+}$-EDTA vacutainer tubes $(0.4 \mathrm{ml} / \mathrm{draw})$. The rat was im- mediately injected with GLP-1 or saline (i3vt). Fifteen, 30, 60, and 120 min after injection, blood was drawn and placed on ice. After the last blood draw, the rats were given $1 \mathrm{ml}$ of saline through the catheter. Blood was then centrifuged (4000 rpm, $15 \mathrm{~min}$ ), and plasma was removed and stored at $-80^{\circ} \mathrm{C}$ until processing.

An additional group of six rats was prepared as described above to test the effects of peripheral administration of GLP-1 on ACTH and corticosterone (CORT) release. Using a within-subjects design, rats were administered saline and 10,100, and $500 \mu \mathrm{g} / \mathrm{kg}$ GLP-1 intraperitoneally. Each rat received each treatment in a randomized manner, with no less than $5 \mathrm{~d}$ between treatments.

\section{Experiment 2: astressin, central GLP-1, and the HPA axis}

Eight rats were implanted with inferior vena cava catheters and third ventricular cannulas, as described in the previous section. After recovery and acclimation time, the rats were subjected to the following treatments $(n=6)$ : intraperitoneal saline $(1 \mathrm{ml})$ plus i3vt saline $(2 \mu \mathrm{l})$, intraperitoneal saline $(1 \mathrm{ml})$ plus i3vt GLP-1 $(1.0 \mu \mathrm{g} / 2 \mu \mathrm{l})$, intraperitoneal astressin (American Peptides; $33 \mu \mathrm{g} / 1 \mathrm{ml}$ ) plus i3vt saline $(2 \mu \mathrm{l})$, and intraperitoneal astressin $(33 \mu \mathrm{g} / 1 \mathrm{ml})$ plus i3vt GLP-1 $(1.0 \mu \mathrm{g} / 2 \mu \mathrm{l})$. Astressin is a nonselective $\mathrm{CRH}$ receptor antagonist, not known to cross the bloodbrain barrier. Thus, when administered peripherally, it likely acts at peripheral CRH receptors to exert its effect.

Blood was drawn from each animal at the start of the light phase. The rats were then immediately injected with the first of the paired injections. Fifteen minutes later, the second injection was made. Fifteen, 30, 60, and 120 min after the second injection, blood was drawn, transferred to a $\mathrm{K}^{+}$-EDTA vacutainer, and placed on ice. At the completion of the session, blood was processed as described in the previous experiment.

\section{Experiment 3: exendin, $\mathrm{LiCl}$, and the HPA axis}

Twenty-four rats were implanted with inferior vena cava catheters and third ventricular cannulas, as described in experiment 1. After recovery and acclimation time, the rats were weight-matched and divided into four groups ( $n=5$ after testing of cannulas and catheters). Each group was subjected to one of the following treatments: i3vt saline $(2 \mu \mathrm{l})$ plus intraperitoneal saline $(0.15 \mathrm{M}$, volume equivalent to $2 \%$ of the animal's body weight), i3vt exendin (des-His ${ }_{1}$, Glu $_{9}$-exendin-4; $50 \mu \mathrm{g} / 2 \mu \mathrm{l}$ ) plus intraperitoneal saline, i3vt saline $(2 \mu \mathrm{l})$ plus intraperitoneal $\mathrm{LiCl}(0.15 \mathrm{M}$, volume equivalent to $2 \%$ of the animal's body weight), and i3vt exendin plus intraperitoneal $\mathrm{LiCl}$. Injections were made, and blood samples were taken and processed as described in Experiment 2.

\section{Experiment 4: exendin, psychogenic stress, and the HPA axis}

Twelve rats were implanted with inferior vena cava catheters and third ventricular cannulas, as described in the previous sections. After recovery and acclimation time, the rats were weight-matched and divided into two groups ( $n=5$ per group). Group 1 received i3vt saline before placement on the elevated plus maze (EPM), and group 2 received exendin $(50 \mu \mathrm{g})$ before placement on the EPM. On the test day, baseline blood was drawn from each rat. The rat was then immediately injected with saline or exendin. Fifteen minutes after injection, the rat was placed on the EPM for $5 \mathrm{~min}$. Blood was drawn 15, 30, 60, and $120 \mathrm{~min}$ after EPM exposure and stored for processing as described in the previous experiments.

\section{Experiment 5: exendin, psychogenic stress, and behavior}

Twenty naive rats were implanted with third ventricular cannulas as described. After verification of cannula placement, the rats were weightmatched and divided into two groups ( $n=8$ per group). Group 1 received saline before EPM exposure, and group 2 received exendin $(50 \mu \mathrm{g})$ before EPM exposure. On the test day, each rat was injected with saline or exendin 15 min before placement on the EPM. The rat was videotaped for $5 \mathrm{~min}$ and later scored by an unbiased observer blinded to the experimental condition. The tapes were scored for the number of entries into the open arms versus the closed arms and for the amount of time spent in the open arms, closed arms, and the center of the maze.

Experiment 6: HPA and behavioral responses to GLP-1 in the CeA and $P V N$

A: Central nucleus of the amygdala, GLP-1, and the HPA axis. Twenty-five male Long-Evans rats (300-375 gm) were implanted with cannulas 

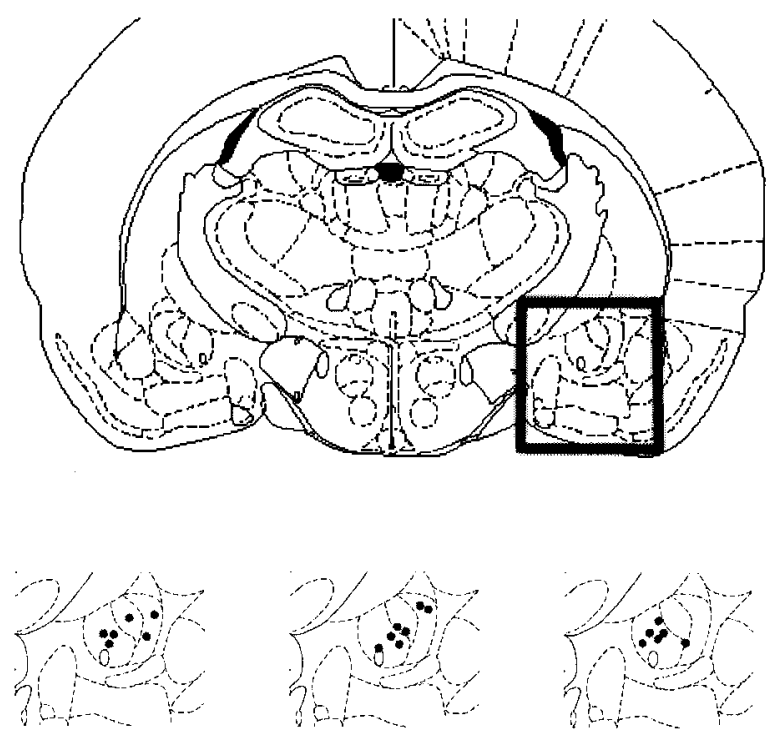

saline $(n=6)$

$0.2 \mu \mathrm{g}$ GLP-1 $(\mathrm{n}=7)$

$1.0 \mu \mathrm{g}$ GLP-1 $(\mathrm{n}=6)$

Figure 1. Central nucleus of the amygdala injection sites. After the completion of the experiments involving CeA-cannulated rats, the animals were killed and given injections of cresyl violet via the (eA cannula. Brains were subsequently sectioned ( $50 \mu \mathrm{m} / \mathrm{section}$ ), and cannula placement was verified. Black dots within the CeA of each bottom diagram represent injection sites for the rats with correctly placed cannulas. Rats whose cannulas were not in the CeA were excluded from the data analyses ( $n=6$ of 25 removed).

aimed at the central nucleus of the CeA $[-2.3 \mathrm{~mm} \mathrm{AP},-4.1 \mathrm{~mm}$ mediolateral (ML), and $-7.4 \mathrm{~mm}$ DV with respect to bregma; Paxinos and Watson, 1997]. After a 2 week recovery period, rats were weight-matched and divided into three groups ( $n=8$ per group): saline, $0.2 \mu \mathrm{g}$ of GLP- 1 , or $1.0 \mu \mathrm{g}$ of GLP-1. All injections were delivered in a volume of $0.5 \mu \mathrm{l}$ of $0.9 \%$ sterile saline via a Hamilton (Reno, NV) syringe over 2 min. Immediately before injection, blood samples were taken via tail vein. After injection, blood was again taken at 30 and $60 \mathrm{~min}$. Blood was collected into heparinized Natelson tubes and then placed in $1.5 \mathrm{ml}$ Eppendorf tubes on ice until the end of the experiment. Blood was then centrifuged at $4^{\circ} \mathrm{C}$ for $15 \mathrm{~min}$ at $4000 \mathrm{rpm}$. Plasma was subsequently extracted and frozen at $-80^{\circ} \mathrm{C}$ until processing.

$B$ : Central nucleus of the amygdala, GLP-1, and psychogenic stress. The rats from the previous experiment were given a $5 \mathrm{~d}$ rest period and again weight-matched and divided into three groups ( $n=8$ per group): saline, $0.2 \mu \mathrm{g}$ of GLP-1, or $1.0 \mu \mathrm{g}$ of GLP-1. All injections were delivered in a volume of $0.5 \mu \mathrm{l}$ of $0.9 \%$ sterile saline via a Hamilton syringe over $2 \mathrm{~min}$. Testing began at the onset of the dark cycle. Each rat was injected with GLP-1 or saline, with groups randomized such that the time of injection after the onset of the dark cycle was randomized (i.e., rat 1 was injected at lights out, and rat 15 was injected 75 min past the onset of the dark cycle). Fifteen minutes after injection the rat was placed on an elevated plus maze for $5 \mathrm{~min}$ and videotaped. Videotapes were later scored as described in Experiment 5.

After completion of these studies, rats were given an overdose of sodium pentobarbital (60 mg/kg, i.p.). Rats were then injected with $0.5 \mu \mathrm{l}$ of cresyl violet via CeA cannula and decapitated. Brains were removed, passively perfused in $4 \%$ paraformaldehyde for $24 \mathrm{hr}$, and then sectioned at $50 \mu \mathrm{m}$ thickness in the coronal plane. Sections were mounted on slides and examined for the presence of dye in the CeA, which indicated correct placement. Rats whose cannulas were not in the CeA were excluded from the data analyses ( $n=6$ removed; Fig. 1 ).

C: Paraventricular nucleus, GLP-1, and the HPA axis. Twenty-two male Long-Evans rats (300-375 gm) were implanted with cannulas aimed at the hypothalamic PVN $(-2.0 \mathrm{~mm} \mathrm{AP},-0.2 \mathrm{~mm} \mathrm{ML}$, and $-7.1 \mathrm{~mm} \mathrm{DV}$
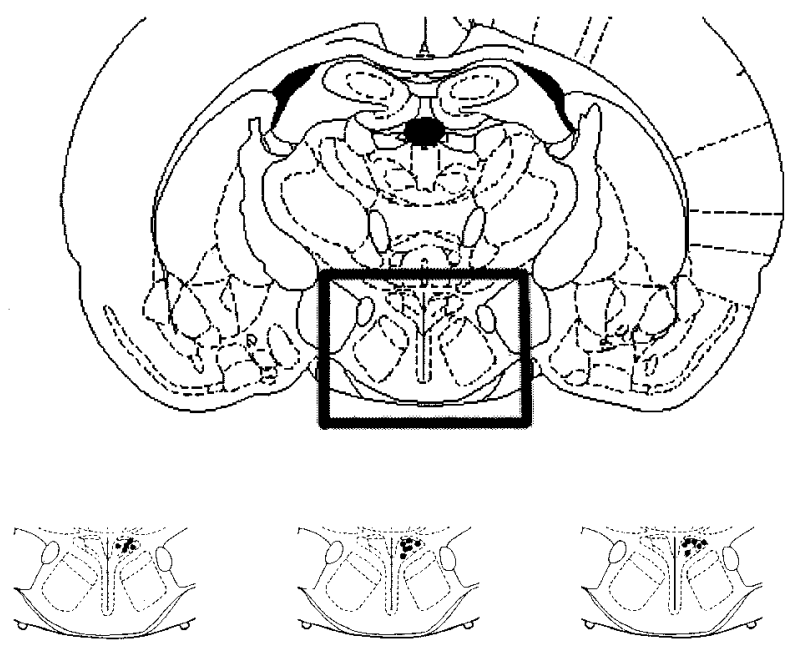

saline $(n=5)$

$0.2 \mu \mathrm{g}$ GLP-1 $(\mathrm{n}=6)$

$1.0 \mu \mathrm{g} \mathrm{GLP}-1(\mathrm{n}=6)$

Figure 2. Paraventricular nucleus of the hypothalamus injection sites. After the completion of the experiments involving PVN-cannulated rats, the animals were killed and given injections of cresyl violet via the PVN cannula. Brains were subsequently sectioned ( $50 \mu \mathrm{m} / \mathrm{section}$ ), and cannula placement was verified. Black dots within the PVN of each bottom diagram represent injection sites for the rats with correctly placed cannulas. Rats whose cannulas were not in the PVN were excluded from the data analyses ( $n=5$ of 22 removed).

with respect to bregma). After a 2 week recovery period, rats were weightmatched and divided into three groups ( $n=7$ per group): saline, $0.2 \mu \mathrm{g}$ of GLP-1, or $1.0 \mu \mathrm{g}$ of GLP-1. All injections were delivered in a volume of $0.5 \mu \mathrm{l}$ of $0.9 \%$ sterile saline via a Hamilton syringe over $2 \mathrm{~min}$. Blood was taken from the tail vein and treated as described in experiment $6 \mathrm{~A}$.

D: Paraventricular nucleus, GLP-1, and psychogenic stress. The rats from the same experiment were given a $5 \mathrm{~d}$ rest period. After this rest period, they were once again weight-matched and divided into three groups $(n=$ 7 per group): saline, $0.2 \mu \mathrm{g}$ of GLP-1, or $1.0 \mu \mathrm{g}$ of GLP-1. All injections were delivered in a volume of $0.5 \mu \mathrm{l}$ of $0.9 \%$ sterile saline via a Hamilton syringe over $2 \mathrm{~min}$. This experiment was conducted as described in experiment $6 \mathrm{~B}$.

After completion of these studies, rats were given an overdose of sodium pentobarbital (60 mg/kg, i.p.). Rats were then injected with $0.5 \mu \mathrm{l}$ of cresyl violet via PVN cannula and decapitated. Brains were removed, passively perfused in $4 \%$ paraformaldehyde for $24 \mathrm{hr}$, and then sectioned at $50 \mu \mathrm{m}$ thickness in the coronal plane. Sections were mounted on slides and examined for the presence of dye in the PVN, which indicated correct placement. The presence of dye was used only as a marker for placement, not as an indication of the spread of the drug, because the spread of dye is unlikely to recapitulate the extent of the spread of the injected peptide. Rats whose cannulas were not in the PVN were excluded from the data analyses ( $n=5$ removed; Fig. 2 ).

\section{Radioimmunoassay}

Plasma ACTH and corticosterone concentrations were determined using ${ }^{125}$ I-labeled rat ACTH (Diasorin, Stillwater, MN) and corticosterone (ICN Biochemicals, Costa Mesa, CA) kits according to manufacturers' instructions. The limits of detection for each kit are $15 \mathrm{pg} / \mathrm{ml}$ and 8 $\mathrm{ng} / \mathrm{ml}$, respectively. For both ACTH and corticosterone assays, all plasma samples were run in duplicate in single assays.

\section{Results}

Experiment 1: GLP-1 and the HPA axis

GLP-1 administration into the third ventricle resulted in elevations in plasma ACTH and CORT, regardless of dose, for 60 min after injections (Fig. 3A,B, respectively). As determined by two-way ANOVA, there was a significant main effect of group 
A

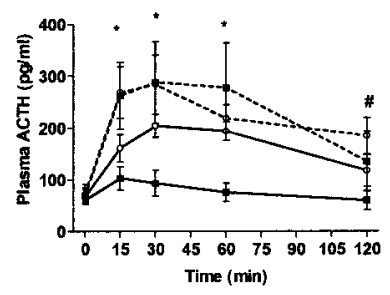

B

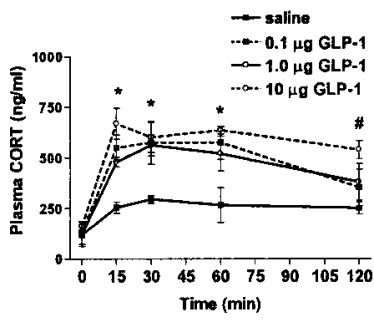

A

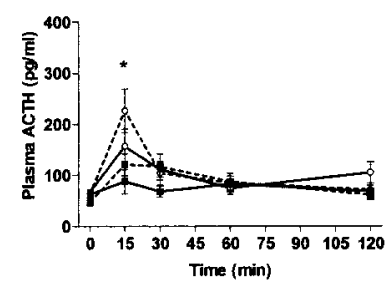

B

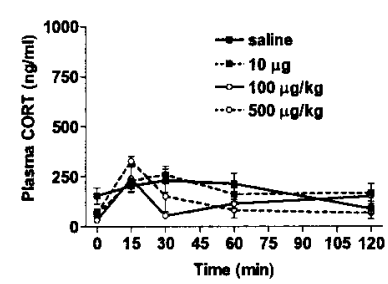

Figure 4. A, Plasma ACTH after intraperitoneal administration of GLP-1. Fifteen minutes after injection (10, 100, and $500 \mu \mathrm{g} / \mathrm{kg}$ or saline), the highest dose of GLP-1 resulted in a significant increase in plasma ACTH $(p<0.05)$. There were no other differences between GLP-1 and saline treatment. B, Plasma CORT after intraperitoneal administration of GLP-1. Intraperitoneal administration of GLP-1 (10, 100, and $500 \mu \mathrm{g} / \mathrm{kg})$ did not elevate plasma CORT. *Highest dose $(500 \mu \mathrm{g} / \mathrm{kg})$ significantly different from saline; $p<0.05$. 政ed the highest dose, plasma CORT remained significantly elevated at $120 \mathrm{~min}$. *All treatment groups significantly different from saline; $p<0.05$. "Highest dose $(10 \mu \mathrm{g})$ significantly different from saline; $p<0.05$.

$\left(F_{(3,16)}=7.091 ; p<0.01\right)$, a significant main effect of time $\left(F_{(4,64)}=23.991 ; p<0.001\right)$, and a significant interaction $\left(F_{(12,64)}=2.453 ; p<0.05\right)$ with regard to plasma ACTH levels. Post hoc analyses [Tukey's honestly significant difference (HSD) test] revealed that at $15 \mathrm{~min}$, all doses resulted in significantly higher plasma ACTH compared with saline-treated rats $(p<$ 0.01 for 0.1 and $10 \mu \mathrm{g} ; p<0.05$ for $1.0 \mu \mathrm{g}$ ). At $30 \mathrm{~min}$ after injection, all groups continued to have significantly elevated ACTH ( $p<0.01$ for 0.1 and $10 \mu \mathrm{g} ; p<0.05$ for $1.0 \mu \mathrm{g}$ ). At 60 min, the significant elevation in ACTH remained for all groups ( $p<0.05$ for all doses), and at $120 \mathrm{~min}$, only the group that received $10 \mu \mathrm{g}$ had significantly elevated ACTH compared with their ACTH response to saline $(p<0.01)$. In the case of plasma CORT levels, two-way ANOVA revealed that i3vt GLP-1 resulted in a significant main effect of group $\left(F_{(3,16)}=10.519 ; p<0.001\right)$, a significant main effect of time $\left(F_{(4,64)}=45.193 ; p<0.001\right)$, and a significant interaction. As determined by post hoc analyses (Tukey's HSD tests), plasma CORT was significantly elevated at $15 \mathrm{~min}$ in all groups compared with their CORT levels after saline treatment $(0.1 \mu \mathrm{g}, p<0.05 ; 1.0 \mu \mathrm{g}, p<0.05 ; 10 \mu \mathrm{g}, p<0.01)$ and at $30 \mathrm{~min}(0.1 \mu \mathrm{g}, p<0.05 ; 1.0 \mu \mathrm{g}, p<0.01 ; 10 \mu \mathrm{g}, p<0.01)$. At $60 \mathrm{~min}$, all doses resulted in significantly elevated CORT levels $(p<0.01)$, and at $120 \mathrm{~min}$, only $10 \mu \mathrm{g}$ of GLP-1 significantly elevated CORT $(p<0.01)$.

In contrast to the effects of i3vt GLP-1 on plasma ACTH and CORT, intraperitoneal administration had minimal effects on these plasma stress hormones. Only the highest dose of GLP-1 $(500 \mu \mathrm{g} / \mathrm{kg})$ significantly elevated plasma ACTH and CORT, and only at the 15 min time point. Plasma ACTH levels after intraperitoneal injection of GLP-1 are depicted in Figure $4 A$. As determined by two-way ANOVA, there was a significant main effect of time $\left(F_{(4,64)}=13.369 ; p<0.01\right)$ and a significant interaction $\left(F_{(12,64)}=2.319 ; p<0.05\right)$. Post hoc analyses (Tukey's HSD test) revealed that at $15 \mathrm{~min}$, only $500 \mu \mathrm{g} / \mathrm{kg}$ resulted in significantly elevated plasma ACTH compared with ACTH after saline treatment $(p<0.01)$. There were no other differences in plasma ACTH after intraperitoneal administration of GLP-1 compared with ACTH after intraperitoneal saline. Analysis of plasma CORT levels after intraperitoneal administration of GLP-1 (Fig. $4 \mathrm{~B}$ ) revealed similar results. As determined by two-way ANOVA, there was no main effect of group; however, there was a main effect of time $\left(F_{(4,64)}=11.759 ; p<0001\right)$ and a significant interaction
A
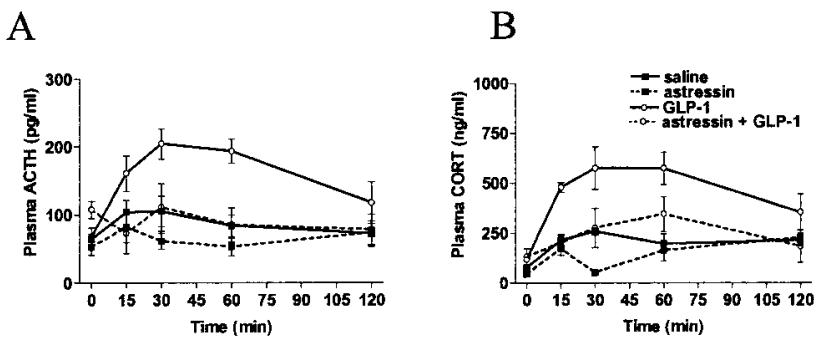

Figure 5. A, Plasma ACTH after CRH receptor antagonism and i3vt GLP-1. CRH receptor antagonism attenuated GLP-1-induced elevations in plasma ACTH. Plasma ACTH was significantly lower in rats treated with the CRH receptor antagonist astressin before $1 \mu \mathrm{g}$ of GLP-1 administered i3vt. $B$, Plasma CORT after CRH receptor antagonism and i3vt GLP-1. CRH receptor antagonism attenuated GLP-1-induced elevations in plasma CORT. Plasma CORT was significantly lower in rats treated with the CRH receptor antagonist astressin before $1 \mu \mathrm{g}$ of GLP-1 administered $\mathrm{i} 3 \mathrm{vt}$ ( $p<0.01$ at 15,30 , and $60 \mathrm{~min}$ ).

$\left(F_{(12,64)}=3.108 ; p<0.01\right)$. Post hoc analyses (Tukey's HSD test) demonstrated that the only time point and dose at which there was a significant elevation in CORT was at 15 min after injection of $500 \mu \mathrm{g} / \mathrm{kg}(p<0.05)$.

\section{Experiment 2: astressin, central GLP-1, and the HPA axis}

Pretreatment with astressin attenuated the ACTH and CORT responses to i3vt GLP-1. Plasma ACTH and CORT levels in response to $\mathrm{CRH}$ receptor antagonism and i3vt GLP-1 are depicted in Figure 5, $A$ and $B$, respectively. In the case of plasma ACTH, two-way ANOVA revealed that there was a significant main effect of group $\left(F_{(3,16)}=9.205 ; p<0.001\right)$, a significant main effect of time $\left(F_{(4,64)}=8.039 ; p<0.001\right)$, and a significant interaction $\left(F_{(12,64)}=4.876 ; p<0.001\right)$. Post hoc analyses (Tukey's HSD tests) demonstrated that at 15,30, and 60 min after the second injection, intraperitoneal saline plus $1.0 \mu \mathrm{g}$ of GLP-1 resulted in significantly elevated plasma ACTH $(p<0.01$ at all three time points) compared with ACTH levels attributable to saline plus saline and astressin plus saline $(p<0.001$ at all three time points). Saline plus GLP-1 treatment resulted in significantly elevated ACTH levels compared with astressin plus GLP-1 treatment at 15, 30, and $60 \mathrm{~min}$ ( $p<0.01$ at all three time points) but not at $120 \mathrm{~min}$. As depicted in Figure 5B, plasma CORT levels were similarly affected by the described treatments. There was a significant main effect of group $\left(F_{(3,16)}=13.540 ; p<0.001\right)$, a significant main effect of time $\left(F_{(4,64)}=18.462 ; p<0.001\right)$, and a significant interaction $\left(F_{(12,64)}=3.944 ; p<0.001\right)$. Post hoc analyses (Tukey's HSD tests) demonstrated that at 15,30, and $60 \mathrm{~min}$ after the second injection, intraperitoneal saline plus $1.0 \mu \mathrm{g}$ of 
A

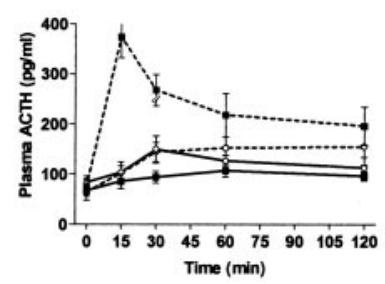

B

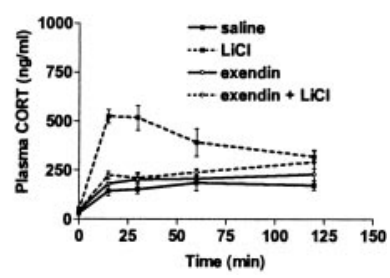

Figure 6. A, Plasma ACTH after GLP-1 receptor antagonism and intraperitoneal LiCl. Plasma ACTH levels were significantly elevated after intraperitoneal administration of $\mathrm{LiCl}$. This effect was attenuated by pretreatment with the GLP-1 receptor antagonist des-His, ${ }_{1} \mathrm{Glu}_{9}$-exendin- 4 (exendin). At 15, 30, 60, and 120 min, saline plus LiCl resulted in significantly elevated ACTH compared with saline plus saline ( $p<0.001 ; p<0.001 ; p<0.01 ; p<0.01$, respectively), compared with exendin plus saline ( $p<0.001$ at $15 \mathrm{~min} ; p<0.01$ at 30 and $60 \mathrm{~min}$; not significantly different at $120 \mathrm{~min}$ ), and compared with exendin plus $\mathrm{LiCl}$ ( $p<0.001$ at $15 \mathrm{~min}$; $p<0.01$ at $30 \mathrm{~min} ; p<0.05$ at $60 \mathrm{~min}$; no difference at $120 \mathrm{~min}$ ). B, Plasma CORT after GLP-1 receptor antagonism and intraperitoneal $\mathrm{LiCl}$. At 15, 30, and $60 \mathrm{~min}$, saline plus $\mathrm{LiCl}$ resulted in significantly elevated CORT compared with saline plus saline ( $p<0.001 ; p<0.001 ; p<0.01$, respectively), compared with exendin plus saline ( $p<0.001$ at 15 and $30 \mathrm{~min} ; p<0.01$ at 60 $\mathrm{min}$ ), and compared with exendin plus $\mathrm{LiCl}(p<0.001$ at 15 and $30 \mathrm{~min} ; p<0.05$ at $60 \mathrm{~min}$ ). There were no significant differences in CORT levels at $120 \mathrm{~min}$.

GLP-1 resulted in significantly elevated plasma CORT $(p<$ $0.001 ; p<0.01 ; p<0.01$, respectively) compared with CORT levels attributable to saline plus saline and astressin plus saline ( $p<0.01$ at all three time points). Saline plus GLP-1 treatment resulted in significantly elevated CORT levels compared with astressin plus GLP-1 treatment at $15(p<0.001)$ and $30(p<0.01)$ min but not at 60 or 120 min (Fig. $5 B$ ). Given that astressin is likely acting systemically rather than centrally, antagonism of peripheral CRH receptors is effective in attenuation of GLP-1induced elevations in plasma glucocorticoids.

\section{Experiment 3: exendin, $\mathrm{LiCl}$, and the HPA axis}

Administration of LiCl elevated plasma ACTH and CORT. These effects were attenuated when animals were treated with a GLP-1 receptor (GLP-1R) antagonist before $\mathrm{LiCl}$ injection. The ACTH and CORT responses after GLP-1R antagonism and LiCl are depicted in Figure 6, $A$ and $B$, respectively. Rats were given one of four treatments, the second injection being administered $15 \mathrm{~min}$ after the first in all cases: i3vt saline $(2 \mu \mathrm{l})$ plus intraperitoneal saline (volume equivalent to $2 \%$ of each rat's body weight), i3vt saline plus intraperitoneal $\mathrm{LiCl}(0.15 \mathrm{M}$, volume equivalent to $2 \%$ of body weight), i3vt exendin ( $50 \mu \mathrm{g}$ in $2 \mu \mathrm{l})$ plus intraperitoneal saline, or i3vt exendin plus intraperitoneal LiCl. Regarding plasma ACTH levels, there was a significant main effect of group $\left(F_{(3,16)}=12.472 ; p<0.001\right)$, a significant main effect of time $\left(F_{(4,64)}=21.523 ; p<0.001\right)$, and a significant interaction $\left(F_{(12,64)}\right.$ $=8.735 ; p<0.001)$. Post hoc analyses determined that at 15,30 , 60 , and $120 \mathrm{~min}$, saline plus $\mathrm{LiCl}$ resulted in significantly elevated ACTH compared with saline plus saline $(p<0.001 ; p<0.001$; $p<0.01 ; p<0.01$, respectively), compared with exendin plus saline $(p<0.001$ at $15 \mathrm{~min} ; p<0.01$ at 30 and $60 \mathrm{~min}$; not significantly different at $120 \mathrm{~min}$ ), and compared with exendin plus $\mathrm{LiCl}(p<0.001$ at $15 \mathrm{~min} ; p<0.01$ at $30 \mathrm{~min} ; p<0.05$ at 60 min; no difference at $120 \mathrm{~min}$ ).

As was true in the previous experiments, plasma CORT levels mirrored plasma ACTH levels. There was a significant main effect of group $\left(F_{(3,16)}=15.090 ; p<0.001\right)$, a significant main effect of time $\left(F_{(4,64)}=47.761 ; p<0.001\right)$, and a significant interaction $\left(F_{(12,64)}=6.703 ; p<0.001\right)$. Post hoc analyses determined that at 15,30 , and $60 \mathrm{~min}$, saline plus $\mathrm{LiCl}$ resulted in significantly ele-

A

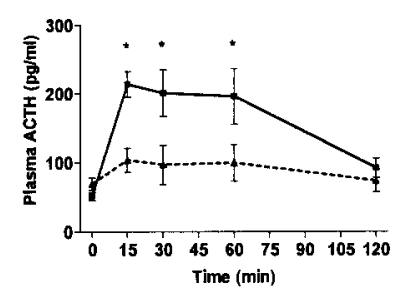

B

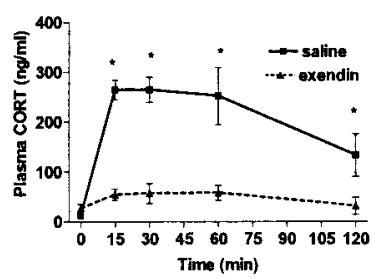

Figure 7. A, Plasma ACTH after GLP-1 receptor antagonism before placement on an isolated open arm of the elevated plus maze. At 15,30, and 60 min after EPM stress, rats that were pretreated with exendin had significantly lower plasma ACTH levels than did saline-treated rats. $B$, Plasma CORT after GLP-1 receptor antagonism before placement on an isolated open arm of the elevated plus maze. At 15, 30, and 60 min after EPM stress, rats that were pretreated with exendin had significantly lower plasma CORT levels than did saline-treated rats. *Significantly different from saline; $p<0.01$.

vated CORT compared with saline plus saline $(p<0.001 ; p<$ $0.001 ; p<0.01$, respectively), compared with exendin plus saline $(p<0.001$ at 15 and $30 \mathrm{~min} ; p<0.01$ at $60 \mathrm{~min})$, and compared with exendin plus $\mathrm{LiCl}(p<0.001$ at 15 and $30 \mathrm{~min} ; p<0.05$ at $60 \mathrm{~min}$ ). There were no significant differences in CORT levels at $120 \mathrm{~min}$.

Experiment 4: exendin, psychogenic stress, and the HPA axis Exposure to elevated platforms results in a robust increase in plasma ACTH and CORT that is dependent on the threat represented by falling from the platform rather than by activation of interoceptive visceral pathways, as in toxin administration. Rats were given an i3vt injection of saline or exendin 15 min before placement on an isolated open arm of the EPM. Rats that were pretreated with saline had significantly elevated plasma ACTH and CORT levels, whereas rats pretreated with exendin had no ACTH or CORT response to EPM stress (Fig. 7A, $B$, respectively). These data were surprising and suggest that signaling through the GLP-1R is involved in the HPA response to a psychogenic stressor.

Experiment 5: exendin, psychogenic stress, and behavior

Because placement on the EPM elicits anxiety-related behaviors as well as HPA activation, we next sought to determine whether the GLP-1 pathway also mediates the behavioral response. Rats were placed in an EPM after receiving saline or the GLP-1R antagonist, and the amount of time spent either in the open or closed arms of the EPM was monitored. The elevated plus maze is a behavioral conflict paradigm, pitting the tendency to explore novelty against the threat imposed by the elevated open arms of the maze. Animals administered anxiolytic drugs increase time spent in the open arms, indicating that being on the EPM creates anxiety or stress (Pellow et al., 1985). In this experiment, rats treated with exendin spent significantly more time in the open arms than the control animals $(50.8 \pm 10.0 \%$ time in the open arms/total time on the EPM by exendin-treated rats vs $15.6 \pm$ $4.6 \%$ time in the open arms/total time on the EPM by salinetreated rats; $p<0.05)$. These data collectively indicate that the CNS GLP-1 system has critical roles in mediating both the HPA and the anxiety responses to the EPM, as well as the HPA response to interoceptive stressors.

\section{Experiment 6: HPA and behavioral responses to GLP-1 in the} CeA and PVN

Although the data using GLP-1R agonists and antagonists are intriguing, the precise neuroanatomical location of the critical 
A

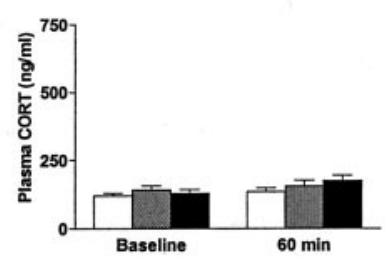

Figure 8. A, Plasma CORT levels in response to administration of GLP-1 directly into the CeA. There was no significant effect of either dose $(0.2$ or $1.0 \mu \mathrm{g})$ on plasma CORT at $60 \mathrm{~min}$ after infusion compared with saline. B, Plasma CORT levels in response to administration of GLP-1 directly into the PVN. Plasma CORT ( 0.2 or $1.0 \mu \mathrm{g}$ ) was significantly elevated at $60 \mathrm{~min}$ after infusion of either 0.2 or $1.0 \mu \mathrm{g}$ of GLP-1 compared with saline; ${ }^{*} p<0.05$.

receptors cannot be determined because i3vt administration will result in widespread activation of cognate receptors distal to the injection site (Bittencourt and Sawchenko, 2000). GLP-1producing cell bodies in the NTS have strong projections to GLP$1 \mathrm{R}$-expressing cell populations in both the PVN and CeA (Han et al., 1986). A wealth of data implicates the PVN as vital to the HPA response to stress, whereas the CeA is critical to anxiety-related behaviors (Koob, 1999). Thus, we predicted that activation of PVN GLP-1 receptors would increase plasma CORT, and activation of CeA GLP-1 receptors would decrease open arm time in the EPM. Separate groups of rats were administered saline or GLP-1 directly into the PVN or CeA. Positions of injection cannula tips are mapped in Figures 1 and 2. Plasma CORT was not significantly elevated after GLP-1 administration in the CeA (Fig. $8 \mathrm{~A}$ ), but the animals spent significantly less time in the open arms of the EPM in response to $0.2 \mu \mathrm{g}$ of GLP-1 $(26.3 \pm 6.3 \%)$ or 1.0 $\mu$ g of GLP-1 $(23.3 \pm 6.2 \%)$ compared with saline (43.2 $\pm 7.6 \%$; $p<0.05$ for both doses). In contrast, rats given GLP-1 directly into the PVN had significantly elevated plasma CORT (Fig. 8 B), with less pronounced anxiety behavior. Rats treated with $0.2 \mu \mathrm{g}$ of GLP-1 before placement on the EPM did not display increased anxiety-like behavior $(42.8 \pm 5.4 \%$ time in the open arms of the EPM) compared with saline-treated controls (45.2 $\pm 6.4 \%$ time in the open arms of the EPM), although this dose did significantly increase plasma CORT (Fig. $8 \mathrm{~B}$ ). However, rats treated with 1.0 mg of GLP-1 did spend significantly less time in the open arms of the EPM $(24.7 \pm 5.9 \%$ time in the open arms $)$ compared with saline-treated controls $(p<0.05)$. These data indicate that stimulation of the HPA axis and anxiety behavior by GLP-1 are mediated at distinct sites in the brain. Moreover, the anxiety behavior elicited by GLP-1 is not secondary to increased CORT but rather is a distinct but coordinated response to GLP-1R activation.

\section{Discussion}

The discovery that NTS GLP-1 pathways are integral to the psychogenic as well as interoceptive stressors studied here is consistent with the broad role for brainstem neurons in the generation of the organismic stress response. Several groups have reported that interoceptive stressors such as LiCl and LPS activate GLP-1 neurons and that GLP-1 receptors play a major role in the neuronal activation, anorexia, and conditioned taste aversions induced by LiCl (Thiele et al., 1997; van Dijk et al., 1997; Rinaman, 1999b; Seeley et al., 2000). Additionally, Larsen et al. (1997) demonstrated that lateral ventricular administration of GLP-1 results in activation in $\sim 80 \%$ of the $\mathrm{CRH}$-positive neurons in the hypophysiotropic medial parvicellular PVN. Given these data, we hypothesized that GLP-1 activates the HPA axis and that antagonism of GLP-1 receptors would attenuate the HPA response to interoceptive stressors such as $\mathrm{LiCl}$. This is the first demonstration that GLP-1 administered directly into the PVN results in activation of the HPA axis. We have found that i3vt GLP-1 potently activates the HPA axis. Antagonism of CRH receptors via peripheral astressin injection attenuates GLP-1-induced elevations in plasma ACTH and CORT. These data are consistent with the hypothesis that GLP-1 activates the HPA axis via increased endogenous $\mathrm{CRH}$ activity, likely at the pituitary. Moreover, GLP-1 antagonists blocked the increased ACTH and CORT caused by LiCl. Thus, the current data extend the role of GLP-1 in mediating LiCl-induced effects (Seeley et al., 2000) to include activation of HPA axis activation. Consequently, GLP-1 appears to play a broad role in the spectrum of responses to interoceptive stimuli such as toxins and mediators of inflammation. The anatomical location of GLP-1-producing neurons (NTS) makes them ideally suited to play a key role in coordinating the recruitment of the appropriate neuronal responses to these interoceptive stressors.

Although the anatomy of GLP-1-producing neurons suggests that involvement of GLP-1 in activation of the HPA axis would be limited to responses to interoceptive stressors, our data indicate the contrary. Psychogenic stressors generally rely on perception of a stress, or the awareness that a situation is threatening. This is in contrast to interoceptive stressors, which result in activation of the HPA axis because of a change in the internal milieu without the requirement of conscious appreciation of the stressors, as well as other types of externally derived stressors that rely on nociceptive or somatosensory stimulation and cognitive processing ( $\mathrm{Li}$ and Sawchenko, 1998). All of these stressors activate the HPA axis; however, the route by which excitation of the PVN occurs is generally believed to differ markedly from that by which interceptive stressors such as $\mathrm{LiCl}$ act. As noted, neuronal activation in the PVN remains intact after medullary knife cuts, which suggests a lack of brainstem involvement in HPA activation after exposure to a psychogenic stressor. However, our data show that not only does a GLP-1 antagonist block the effect of the EPM to increase plasma ACTH and CORT, it also decreases anxiety-like behaviors in the EPM. The discrepancy may be attributable to either a different anatomy of GLP-1 and catecholaminergic systems or to factors associated with the two testing paradigms. Catecholamine-synthesizing enzymes and GLP-1 do not colocalize in the NTS (Larsen et al., 1997b). Although it is highly likely that catecholaminergic and GLP-1 axons use the same ascending trajectory, it remains possible that the medullary knife cuts may spare axons of GLP-1 neurons and thereby account for PVN c-Fos induction in lesion-foot shocked animals. Alternatively, the psychogenic stress paradigm of $\mathrm{Li}$ and Sawchenko (1998) preexposed animals to the shock apparatus for several days before foot shock, whereas our testing was performed on naive animals. Thus, repeated exposure to the testing environment may activate forebrain circuitry capable of registering dissonance of the novel stressful stimulus (shock) in the previously safe environment, allowing initiation of the PVN response in the absence of brainstem input.

A specific forebrain role of GLP-1 in stress regulation is also indicated by the ability of CeA microinjection to selectively increase anxiety-like behavior, with no measurable effect on the HPA axis, whereas GLP-1 in the PVN elicits an HPA response at a lower dose than that required to elicit a behavioral response. Whereas spread of injected material is always a concern for these types of studies, the rich localization of GLP-1 receptors in the $\mathrm{CeA}$ and PVN as opposed to surrounding nuclei (Goke et al., 
1995; Merchenthaler et al., 1999) and the congruence between GLP-1 effects and known functions of the CeA and PVN are consistent with the hypothesis that GLP-1 effects are mediated by these respective regions. Together these data indicate involvement of GLP-1, the central source of which is exclusively in the brainstem, in mediating responses to categorically different stressors.

It is important to note that the current findings are in contrast to those reported for GLP-1 receptor knock-out (GLP-1R-/-) mice. These mice display more anxiety-like behavior when placed on an EPM compared with GLP-1R+/+ mice. Additionally, male GLP-1R-/- mice had significant increases in plasma CORT in response to handling and transport (MacLusky et al., 2000). Potential explanations for this discrepancy include developmental compensation in the knock-out mouse, species differences between rat and mouse, and differences in experimental paradigms. Further experiments will be necessary to test these possibilities.

As roles for GLP-1 in the mediation of satiety (TangChristensen et al., 1996; Turton et al., 1996; McMahon and Wellman, 1997), visceral illness (van Dijk et al., 1997; Rinaman 1999a,b; Seeley et al., 2000; Kinzig et al., 2002), and sympathetic outflow (Yamamoto et al., 2002) emerge, so does a role for GLP-1 in the activation of the HPA axis. Although GLP-1-producing neurons within the caudal brainstem would seem ideally situated to receive information about various aspects of the animal's internal state (interoceptive input), the finding that brainstem systems are involved in limbic responses generated to perceived or anticipated stressors (psychogenic) challenges current models of stress neurological circuits. Detection of toxins or their visceral effects is likely communicated by vagal or sympathetic afferents from the periphery or by direct sensing of toxins in the blood by areas lacking a blood-brain barrier (e.g., the area postrema). All of these inputs clearly impinge directly on GLP-1 neurons in the NTS. The innate response to heights, however, represents a brain-generated response to a "perceived" threat, relying on cortical and limbic structures to produce behavioral and neuroendocrine sequelae. Because GLP-1-producing neurons are limited to the brainstem, the present data argue that HPA responses to both classes of stressors (exemplified by the elevated plus maze and $\mathrm{LiCl}$ ) are mediated by an ascending pathway from the brainstem. The discovery that GLP-1R blockade reduces the response to both these types of stressor argues against mutual exclusiveness of psychogenic and interoceptive stress circuitry (Herman and Cullinan, 1997; Sawchenko et al., 2000). As such, it appears that forebrain structures interpreting psychogenic stimuli modulate HPA stress responses by way of descending projections to the NTS. In support of this hypothesis, many forebrain limbic sites, such as the central nucleus of the amygdala and infralimbic cortex, send direct projections to this region (Schwaber et al., 1982; van der Kooy et al., 1984; Hurley et al., 1991). Thus, our data suggest that psychogenic stress pathways are not distinct from interoceptive circuits but are in fact layered on top of them. This hierarchical organization patterns limbic-PVN interactions in the hypothalamus (Herman et al., 1996) and suggests that, as a rule, psychogenic influences on the stress responses traverse neurological circuits critical for homeostatic regulation.

Although previous studies have identified limbic forebrain structures as important in anxiety, the site of interaction of these areas with hindbrain regions is thought to be particularly relevant to the autonomic reaction that is associated with fear and is a core symptom of panic disorder. Given the current data demonstrating a role for GLP-1 in anxiety and recent reports of the involve- ment of GLP-1 in the regulation of sympathetic outflow, it appears that although forebrain processing of psychogenic stressors may be crucial to the neuroendocrine and behavioral responses to these stressors, there is also a hindbrain component that has thus far been mostly neglected. It is possible that the contribution of the central GLP-1 system to the psychogenic stress response is via its mediation of the sympathetic component. It has recently been reported by others that there are a number of GLP-1responsive catecholamine neurons in the area postrema that innervate autonomic control sites (Yamamoto et al., 2003). GLP1 -induced increases in heart rate and blood pressure would then, in this case, be responsible for subsequent increases in both HPA activity and anxiety-like behavior.

In summary, we have demonstrated that the GLP-1 system and, by extension, the NTS in general play a central role in the processing of interoceptive and psychogenic stressors. In doing so, we have identified a previously unrecognized role for the CNS GLP-1 system in regulating stress responses and anxiety. These results have two important clinical implications. First, GLP-1 agonists are currently in advanced clinical development primarily for the treatment of diabetes via the GLP-1 systemic effect to increase glucose-dependent insulin secretion and other actions that promote glucose lowering (Drucker, 1990). The current data indicate that great care must be taken to prevent their penetration into the CNS, where they may inappropriately recruit stress responses and contribute to stress-related diseases. Second, the broad role GLP-1 plays in mediating different aspects of the stress response implies that treatments that reduce GLP-1 signaling in the CNS may be viable options for the treatment of a variety of debilitating conditions ranging from panic attacks and anxiety disorders to affective disorders associated with HPA dysregulation, such as depression.

\section{References}

Bittencourt JC, Sawchenko PE 2000 Do centrally administered neuropeptides access cognate receptors? An analysis in the central corticotropinreleasing factor system. J Neurosci 20:1142-1156.

Charney DS, Deutch AY, Krystal JH, Southwick SM, Davis M (1993) Psychobiologic mechanisms of posttraumatic stress disorder. Arch Gen Psychiatry 50:295-305.

Drucker DJ (1990) Glucagon and the glucagon-like peptides. Pancreas 5:484-488.

Goke R, Larsen PJ, Mikkelsen JD, Skeikh SP (1995) Distribution of GLP-1 binding sites in the rat brain: evidence that exendin is a ligand of brain GLP-1 sites. Eur J Neurosci 7:2294-2300.

Grillon C, Southwick SM, Charney DS (1996) The psychobiological basis of posttraumatic stress disorder: association between an agouti-related protein gene polymorphism and anorexia nervosa. Mol Psychiatry $1: 278-297$.

Habib KE, Gold PW, Chrousos GP (2001) Neuroendocrinology of stress. Endocrinol Metab Clin North Am 30:695-728.

Han VKM, Hynes MA, Jin C, Towle AC, Lauder JM, Lund PK (1986) Cellular localization of proglucagon/glucagon-like peptide 1 messenger RNAs in rat brain. J Neurosci 16:97-107.

Herman JP, Cullinan WE (1997) Neurocircuitry of stress: central control of the hypothalamo-pituitary-adrenocortical axis. Trends Neurosci 20:78-84.

Herman JP, Prewitt CM, Cullinan WE (1996) Neuronal circuit regulation of the hypothalamo-pituitary-adrenocortical stress axis. Crit Rev Neurobiol 10:371-394.

Hurley KM, Herber H, Moga MM, Saper CB (1991) Efferent projections of the infralimbic cortex in the rat. J Comp Neurol 308:249-276.

Jin SL, Han VKM, Simmons JG, Towle AC, Lauder JM, Lund PK (1988) Distribution of glucagon like peptide 1, glucagon, and glicentin in the rat brain: an immunocytochemical study. J Comp Neurol 271:519-532.

Kathol RG, Anton R, Noyes R, Gehris T (1989) Direct comparison of urinary free cortisol excretion in patients with depression and panic disorder. Biol Psychiatry 25:873-878. 
Kinzig KP, D’Alessio DA, Seeley RJ (2002) The diverse roles of CNS GLP-1 in the control of food intake and the mediation of visceral illness. J Neurosci 22:10470-10476.

Koob GF 1999 Corticotropin-releasing factor, norepinephrine, and stress. Biol Psychiatry 46:1167-1180.

Landfield PW, Eldridge JC (1991) The glucocorticoid hypothesis of brain aging and neurodegeneration: recent modifications. Acta Endocrinol (Copenh) 125 [Suppl 1]:54-64.

Larsen PJ, Tang-Christensen M, Jessop DS (1997a) Central administration of glucagon-like peptide-1 activates hypothalamic neuroendocrine neurons in the rat. Endocrinology 138:4445-4455

Larsen PJ, Tang-Christensen M, Holst JJ, Orskov C (1997b) Distribution of glucagon-like peptide-1 and other preproglucagon-derived peptides in the rat hypothalamus and brainstem. Neuroscience 77:257-270.

Li HY, Sawchenko PE (1998) Hypothalamic effector neurons and extended circuitries activated in "neurogenic" stress: a comparison of footshock effects exerted acutely, chronically, and in animals with controlled glucocorticoid levels. J Comp Neurol 393:244-266.

Li HY, Ericsson A, Sawchenko PE (1996) Distinct mechanisms underlie activation of hypothalamic neurosecretory neurons and their medullary catecholaminergic afferents in categorically different stress paradigms. Proc Natl Acad Sci USA 93:2359-2364.

MacLusky NJ, Cook S, Scrocchi L, Shin J, Kim J, Vaccarino F, Asa SL, Drucker DJ (2000) Neuroendocrine function and response to stress in mice with a complete disruption of glucagon-like peptide-1 signaling. Endocrinology 141:752-762.

McEwen BS, Stellar E (1993) Stress and the individual: mechanisms leading to disease. Arch Intern Med 153:2093-2101.

McMahon LR, Wellman PJ (1997) PVN infusion of GLP-1(7-36) amide suppresses feeding and drinking but does not induce conditioned taste aversions or alter locomotion in rats. Am J Physiol 274:R23-R29.

Merchenthaler I, Lane M, Shughrue P (1999) Distribution of pre-proglucagon and glucagon-like peptide-1 receptor messenger RNAs in the rat central nervous system. J Comp Neurol 403:261-280.

Paxinos G, Watson C (1997) The rat brain in stereotaxic coordinates, Ed 3. New York: Academic.

Pellow S, Chopin P, File SE, Briley M (1985) Validation of open:closed arm entries in an elevated plus-maze as a measure of anxiety in the rat. J Neurosci Methods 14:149-167.
Rinaman L (1999a) Interoceptive stress activates glucagon-like peptide-1 neurons that project to the hypothalamus. Am J Physiol 277:R582-R590.

Rinaman L (1999b) A functional role for central glucagon-like peptide-1 receptors in lithium chloride-induced anorexia. Am J Physio 277:R1537-R1540.

Sawchenko PE, Li HY, Ericsson A (2000) Circuits and mechanisms governing hypothalamic responses to stress: a tale of two paradigms. Prog Brain Res 122:61-78.

Schwaber JS, Kapp BS, Higgins GA, Rapp PR (1982) Amygdaloid and basal forebrain direct connections with the nucleus of the solitary tract and the dorsal motor nucleus. J Neurosci 2:1424-1438.

Seeley RJ, Blake K, Rushing PA, Benoit SC, Eng J, Woods SC, D’Alessio D (2000) The role of CNS GLP-1-(7-36) amide receptors in mediating the visceral illness effects of lithium chloride. J Neurosci 20:1616-1621.

Tang-Christensen M, Larsen PJ, Goke R, Fink-Jensen A, Jessop DS, Moller M, Sheikh SP (1996) Central administration of GLP-1-(7-36) amide inhibits food and water intake in rats. Am J Physiol 271:R848-R856.

Thiele TE, van Dijk G, Campfield LA, Smith FJ, Burn P, Woods SC, Bernstein IL, Seeley RJ (1997) Central administration of GLP-1, but not leptin, produce conditioned taste aversions in the rat. Am J Physio 272:R726-R730.

Turton MD, O'Shea D, Gunn I, Beak SA, Edwards CMB, Meeran K, Choi SJ, Taylor GM, Heath MM, Lambert PD, Wilding JPH, Smith DM, Ghatei MA, Herbert J, Bloom SR (1996) A role for glucagon-like peptide-1 in the central regulation of feeding. Nature 379:69-72.

van der Kooy D, Koda LY, McGinty JF, Gerfen CR, Bloom FE (1984) The organization of projections from the cortex, amygdala, and hypothalamus to the nucleus of the solitary tract in rat. J Comp Neurol 224:1-24.

van Dijk G, Thiele TE, Seeley RJ, Woods SC, Bernstein IL (1997) Glucagonlike peptide-1 and satiety? Nature 385:214

Yamamoto H, Lee CE, Marcus JN, Williams TD, Overton JM, Lopez ME, Hollenberg AN, Baggio L, Saper CB, Drucker DJ, Elmquist JK (2002) Glucagon-like peptide-1 receptor stimulation increases blood pressure and heart rate and activates autonomic regulatory neurons. J Clin Invest 110:43-52.

Yamamoto H, Kishi T, Lee CE, Choi BJ, Fang H, Hollenberg AN, Drucker DJ, Elmquist JK (2003) Glucagon-like peptide-1-responsive catecholamine neurons in the area postrema link peripheral glucagon-like peptide-1 with central autonomic control sites. J Neurosci 23:2939-2946. 